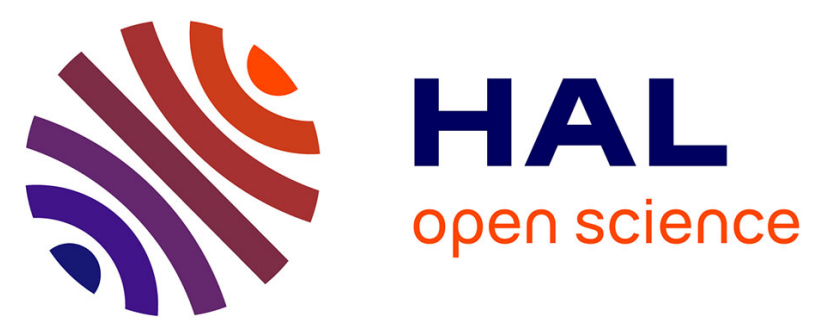

\title{
CD147 overexpression allows an accurate discrimination of bladder cancer patients' prognosis
}

\author{
Julieta Afonso, Adhemar Longatto-Filho, Fátima Baltazar, Nuno Sousa, \\ Francisca Emanuel Costa, António Morais, Teresina Amaro, Carlos Lopes, \\ Lúcio Lara Santos
}

\section{To cite this version:}

Julieta Afonso, Adhemar Longatto-Filho, Fátima Baltazar, Nuno Sousa, Francisca Emanuel Costa, et al.. CD147 overexpression allows an accurate discrimination of bladder cancer patients' prognosis. EJSO - European Journal of Surgical Oncology, 2011, 37 (9), pp.811. 10.1016/j.ejso.2011.06.006 . hal-00723454

\section{HAL Id: hal-00723454 \\ https://hal.science/hal-00723454}

Submitted on 10 Aug 2012

HAL is a multi-disciplinary open access archive for the deposit and dissemination of scientific research documents, whether they are published or not. The documents may come from teaching and research institutions in France or abroad, or from public or private research centers.
L'archive ouverte pluridisciplinaire HAL, est destinée au dépôt et à la diffusion de documents scientifiques de niveau recherche, publiés ou non, émanant des établissements d'enseignement et de recherche français ou étrangers, des laboratoires publics ou privés. 


\section{Accepted Manuscript}

Title: CD147 overexpression allows an accurate discrimination of bladder cancer patients' prognosis

Authors: Julieta Afonso, B.Sc., M.Sc. Adhemar Longatto-Filho, B.Sc., Ph.D., P.M.I.A.C. Fátima Baltazar, B.Sc., Ph.D. Nuno Sousa, M.D. Francisca Emanuel Costa, B.Sc., M.Sc. António Morais, M.D. Teresina Amaro, M.D. Carlos Lopes, M.D., Ph.D. Lúcio Lara Santos, M.D., Ph.D.

PII: S0748-7983(11)00321-0

DOI: 10.1016/j.ejso.2011.06.006

Reference: $\quad$ YEJSO 3180

To appear in: European Journal of Surgical Oncology

Accepted Date: 13 June 2011

Please cite this article as: Afonso J, Longatto-Filho A, Baltazar Fátima, Sousa N, Costa FE, Morais A, Amaro T, Lopes C, Santos L. CD147 overexpression allows an accurate discrimination of bladder cancer patients' prognosis, European Journal of Surgical Oncology (2011), doi: 10.1016/ j.ejso.2011.06.006

This is a PDF file of an unedited manuscript that has been accepted for publication. As a service to our customers we are providing this early version of the manuscript. The manuscript will undergo copyediting, typesetting, and review of the resulting proof before it is published in its final form. Please note that during the production process errors may be discovered which could affect the content, and all legal disclaimers that apply to the journal pertain. 


\section{Original Article}

\section{Title}

CD147 overexpression allows an accurate discrimination of bladder cancer patients' prognosis

\section{Authors}

- Julieta Afonso, B.Sc., M.Sc. ${ }^{a}$ b

- Adhemar Longatto-Filho, B.Sc., Ph.D., P.M.I.A.C. ${ }^{\text {a, } c}$

- Fátima Baltazar, B.Sc., Ph.D. ${ }^{a}$

- Nuno Sousa, M.D. ${ }^{d}$

- Francisca Emanuel Costa, B.Sc., M.Sc. ${ }^{\text {a }}$

- António Morais, M.D. e

- Teresina Amaro, M.D. ${ }^{f}$

- Carlos Lopes, M.D., Ph.D. ${ }^{g}$

- Lúcio Lara Santos, M.D., Ph.D. h, i

\section{Affiliations}

a Life and Health Sciences Research Institute - ICVS, School of Health Sciences, University of Minho, Braga, Portugal

${ }^{\mathrm{b}}$ Alto Ave Superior Institute of Health - ISAVE, Póvoa de Lanhoso, Portugal

c Laboratory of Medical Investigation (LIM 14), Faculty of Medicine, São Paulo State University, São Paulo, Brazil

d Department of Medical Oncology, Portuguese Institute of Oncology - IPO, Porto, Portugal

e Department of Urology, Portuguese Institute of Oncology - IPO, Porto, Portugal

${ }^{f}$ Department of Pathology, Portuguese Institute of Oncology - IPO, Porto, Portugal

${ }^{9}$ Research Center, Portuguese Institute of Oncology - IPO, Porto, Portugal

h Department of Surgical Oncology, Portuguese Institute of Oncology - IPO, Porto, Portugal

' University Fernando Pessoa - UFP, Porto, Portugal

\section{Address for correspondence:}

Lúcio Lara Santos, M.D., Ph.D.

Department of Surgical Oncology, Portuguese Institute of Oncology (IPO)

Rua Dr. António Bernardino de Almeida, 4200-072, Porto, Portugal

Tel: +351-22-5084000; Fax: +351-22-5084001; E-mail: llarasantos@gmail.com 


\section{ABSTRACT}

Background Urothelial bladder carcinoma (UBC) is a chemo-sensitive tumour, but the response to treatment is heterogeneous. CD147 has been associated with chemotherapy resistance. We aimed to define tumours with an aggressive phenotype by the combined analysis of clinicopathological and biological parameters.

Methods 77 patients with T1G3 or muscle-invasive UBC treated by radical cystectomy were studied. Immunohistochemistry was performed to detect CD147, heparanase, CD31 (blood vessels identification) and D2-40 (lymphatic vessels identification) expressions. The immunohistochemical reactions were correlated with the clinicopathological and the outcome parameters. 5-year disease free survival (DFS) and overall survival (OS) rates were estimated using the Kaplan-Meier method. Multivariate analysis was performed by Cox proportional hazards analysis.

Results The 5-year DFS and OS rates were significantly influenced by the classical clinicopathological parameters, and by the occurrence of lymphovascular invasion. CD147 and heparanase immunoexpression did not affect patients' outcome. However, patients with pT3/pT4 tumours had a median OS time of 14.7 months (95\% CI 7.122.3, $p=0.003$ ), which was reduced to 9.2 months (95\% CI 1.5-17.0, $p=0.008$ ) if the tumours were CD147 positive. We developed a model of tumour aggressiveness using parameters as stage, grade, lymphovascular invasion and CD147 immunoexpression, which separated a low aggressiveness from a high aggressiveness group, remaining as an independent prognostic factor of DFS (HR 3.746; 95\% CI 1.244-11.285; $p=0.019$ ) and OS (HR 3.247; 95\% CI 1.015-10.388, $p=0.047)$.

Conclusion CD147 overexpression, included in a model of UBC aggressiveness, may help surgeons to identify patients who could benefit from a personalized therapeutic regimen. Additional validation is needed.

\section{KEYWORDS}

Bladder cancer, CD147, heparanase, lymphovascular invasion, scoring system 


\section{INTRODUCTION}

Bladder cancer is the second most common tumour of the urogenital tract; urothelial bladder carcinoma (UBC) comprises about $90 \%$ of all primary bladder malignancies $[1,2]$. The debate about the best treatment approach for T1G3 and advanced urothelial carcinoma continually challenges all urologic surgeons and oncologists [3, 4]. Chemo-responsiveness of UBC to several drugs has been proved [5]. However, adjuvant systemic chemotherapy does not reveal benefits [6] and neoadjuvant chemotherapy is not yet accepted as the best approach in invasive bladder cancer $[7,8]$. The treatment of UBC may be improved if we understand the molecular events that occur in tumour progression, identifying potential targets to, ultimately, achieve "personalized therapy". In this line of investigation, Takata and colleagues [9] observed that SLC16A3 (solute carrier family 16 - monocarboxylic acid transporter 4 - MCT4, member 3) is up-regulated in patients that do not respond to neoadjuvant M-VAC (methotrexate, vinblastine, doxorubicin and cisplatin) therapy. SLC16A3 (MCT4) is closely associated with CD147 [10], a highly glycosylated cell surface transmembrane protein which stimulates matrix metalloproteinases synthesis and angiogenesis in tumour local environment [11]. CD147 seems to be related with cisplatin resistance of bladder cancer [12]. Overexpression of CD147 in patients with bladder cancer associates with poor prognosis $[13,14]$.

Heparanase is an endoglycosidase that can selectively degrade heparan sulfate glycosaminoglycans and has been shown to play a role in tumour angiogenesis and metastasis [15]. Previous studies have demonstrated that overexpression of heparanase in human tumours, including bladder cancer, facilitates their invasive activity [16]; heparanase and VEGF-C (vascular endothelial growth factor-C, a lymphatic molecular player) co-expression is related with the occurrence of lymphangiogenesis [17].

Angiogenesis and lymphangiogenesis are essential for tumour progression and metastasis, by promoting oxygenation and fluid drainage, and establishing potential routes of dissemination [18]. Lymphovascular invasion has been suggested as a prognostic factor in several malignancies, including bladder cancer [19-21].

In order to define tumours with an aggressive phenotype, we evaluated the expression of CD147, heparanase, and lymphovascular invasion in 77 UBC patients admitted in our Institution and treated by radical cystectomy (RC). 


\section{MATERIALS AND METHODS}

\section{Patients and Tumour Samples}

Data from patients who were clinically diagnosed with high risk of progression non-muscle invasive, cT2 and CT3 (M0) bladder tumours, and treated by RC at the Portuguese Institute of Oncology, Porto, from January 1996 to December 2005, were reviewed retrospectively. During this period, 223 RCs were performed in our institution. For our study we excluded patients diagnosed with squamous cell or adenocarcinomas, patients who received radiation, neoadjuvant or adjuvant chemotherapy, and patients who had an insufficient follow-up time and/or whose tumour samples were inadequate for preparation purposes. Thus, the definitive analysis was based on 77 patients. Each cystectomy specimen was examined according to the College of American Pathologists [22]. Hematoxylin-eosin (H\&E)-stained sections were reviewed according to standard histopathological examination by two independent pathologists. Staging and grading were conducted according to the American Joint Committee on Cancer [23] and to the World Health Organization [24] classification systems, respectively. For statistical analysis, tumours were divided into three groups based on T stage: group 1 (high risk of progression non-muscle invasive bladder tumours, including pT1 and pTis stages), group 2 (pT2 a and b) and group 3 (рT3 and pT4). Table 1 summarizes the clinicopathological parameters.

Sixty-one patients had RC as their first treatment, while the non-muscle invasive tumours $(n=16)$ had previous therapeutic TUR and BCG; these patients were treated by RC following disease progression. Mean and median follow-up were 35.5 and 21.1 months (range 1-132), respectively. During this period, seven cases were lost to follow-up. Recurrence was defined as the reappearance of UBC (loco-regional dissemination or distant metastasis) more than 3 months after RC. Disease-free survival (DFS) was defined as the time from the RC until the recurrence. Overallsurvival (OS) was defined as the time from the RC until death by cancer or the last clinical assessment.

Tumour samples were analysed for CD147 and heparanase expression, and for occurrence of embolic blood vessel (highlighted by CD31 staining) invasion and lymphatic vessel (highlighted by D2-40 staining) invasion by isolated malignant cells, as previously described [21]. All immunohistochemical reactions were correlated with the clinicopathological parameters and the outcome variables (5-year DFS and OS). 


\section{Immunohistochemistry}

Immunohistochemical staining was carried out with the streptavidin-biotinperoxidase complex technique to detect CD147, heparanase and CD31, as previously described for CD31 expression analysis [21], and with the avidin-biotin-peroxidase complex assay to detect D2-40, as previously described [21]. The primary antibodies were obtained from Zymed $\AA$ Laboratories (CD147), Santa Cruz Biotechnology $®$ (heparanase) and DakoCytomation ${ }^{\circledR}(C D 31$ and D2-40). These were used in 1:500 dilution (CD147), 1:100 dilution (CD31 and D2-40) and 1:75 dilution (heparanase), and incubated on the sections for $120 \mathrm{~min}$ (CD147) or $60 \mathrm{~min}$ (heparanase and CD31) at room temperature, or overnight (D2-40) at $4^{\circ} \mathrm{C}$.

Negative controls were carried out by omitting the primary antibodies. Sections of positive controls were used as indicated by the manufacturers (invase ductal breast carcinoma for CD147 and CD31 detection, gastric mucosa for heparanase detection and tonsil for D2-40 detection).

\section{Evaluation of Staining}

The immunostained sections were examined by light microscopy and all sections were evaluated without knowledge of clinical status by two independent observers (T.A. and A.L.-F.).

The positive expressions of CD147 and heparanase were semi-quantitatively assessed using $\times 200$ amplification, considering membrane and cytoplasmic staining of urothelial malignant cells. The positive reactions were assessed in hotspot areas were urothelial malignant cells were present and stained. For each case, 10 fields with at least 100 malignant cells each were evaluated. The following grading system was used for CD147 assessment: negative (-), expression in less than $5 \%$ of cells; and positive $(+)$ expression in over $5 \%$ of cells. For heparanase detection, samples were scored as negative $(-)$, expression in less than $50 \%$ of cells; and positive $(+)$, expression in over $50 \%$ of cells.

The occurrence of BVI and LVI was evaluated based on CD31 (blood endothelial cells marker) and D2-40 (lymphatic endothelial cells marker) positive vessels' assessment, as previously described [21]. We only considered BVI by emboli of wellcharacterized malignant cells surrounded by endothelial cells highlighted by specific positive immunohistochemical expression for CD31; LVI was considered when at least one well-characterized malignant cell was surrounded by endothelial cells highlighted by specific positive immunohistochemical expression for D2-40. 


\section{Statistical analysis}

Data were analyzed using the Statistical Package for Social Sciences (SPSS) software, version 16.0. The relationship between the immunohistochemical markers expression and the clinicopathological parameters was examined for statistical significance using Pearson's chi-square $\left(\kappa^{2}\right)$ test and Fisher's exact test (when $\left.n<5\right)$. The Mann-Whitney test was used for continuous variables. 5-year DFS and OS were evaluated using Kaplan-Meier curves and differences were analysed by Log-Rank or Breslow tests. Variables that achieved statistical significance $(p<0.05)$ in the univariate analysis were entered in a multivariate analysis using Cox proportional hazards analysis. The hazard ratios (HR) were estimated with their $95 \%$ confidence intervals $(95 \% \mathrm{CI})$. 


\section{RESULTS}

\section{Prognostic Significance of Clinicopathological Parameters}

Table 2 shows the prognostic significance of the clinicopathological parameters. T3/T4 pathologic stage, grade III, infiltrating type of lesion and occurrence of lymphovascular invasion and/or loco-regional dissemination lowered significantly the 5year DFS and OS rates.

\section{Clinical and Prognostic Significance of Biological Parameters}

According to the grading system used for CD147 assessment, 18 cases were negative and 59 were positive. A different pattern of expression was observed between non-muscle invasive and invasive tumours (considering membrane staining) (Figure 1). In the first group, the superficial malignant cells were preferentially stained; in the second group, the inner layers were stained. CD147 immunoexpression did not correlate with the clinicopathological parameters or patients' outcome (Table 2). However, it added predictive power of outcome to pathologic stage: patients with pT3/pT4 tumours had a median OS time of 14.7 months (95\% CI 6.9-22.6, $p=0.004$ ), which was reduced to 9.2 months ( $95 \%$ CI $1.5-17.0, p=0.008)$ if the tumours were CD147 positive.

All cases showed some degree of heparanase immunoexpression (Figure 1), although 42 were graded as negative. Normal urothelium was not stained. Positive cases $(n=35)$ exhibited a heterogeneous pattern, with the invasive front being significantly more intensely stained than the tumour core. No association was found between heparanase immunoexpression and clinicopathological parameters or patients' outcome (Table 2).

Although the occurrence of embolic BVI (11 cases) did not correlate with the clinicopathological parameters, it affected significantly patients' prognosis ( $p=0.004$ for 5-year DFS and $p=0.002$ for 5-year OS) (Table 2). Occurrence of LVI by isolated malignant cells (31 cases) was significantly correlated with pT3/pT4 stage $(p=0.008)$ and infiltrating type of lesion $(p=0.007)$, and had a significant impact in outcome ( $p=0.038$ for 5 -year DFS and $p=0.044$ for 5 -year OS) (Table 2).

\section{Development of a Tumour Aggressiveness Scoring System}

We developed a scoring system of tumour aggressiveness as a categorical variable using clinicopathological (stage and grade) and molecular (BVI and LVI) 
factors closely related with disease recurrence and tumour-specific death, as determined in the univariate analysis of 5-year DFS and OS. Additionally, we decided to include CD147 immunoexpression in the model, due to its known biological relevance as a prognostic factor probably associated with chemotherapy resistance [12-14], and to the significant influence of the expression of this parameter in the OS of patients with pT3/pT4 tumours included in our series. For statistical analysis, we considered two groups: group 1 (low aggressiveness profile), in which cases with none, one or two of the above mentioned parameters were present; group 2 (high aggressiveness profile), which included cases with three to five positive parameters. The model revealed a significant association with 5 -year DFS $(p<0.001)$ and OS rates $(p<0.001)$ (Table 2, Figure 2). The rate of CD147 immunoexpression was significantly different between the low aggressiveness profile ( $60 \%$ of cases were CD147 positive) and the high aggressiveness profile ( $87.2 \%$ of cases were CD147 positive) $(p=0.012)$.

\section{Multivariate Analysis}

In multivariate analysis, we included the parameters that significantly influenced the 5-year DFS and OS rates and that were entered in the tumour aggressiveness scoring system proposed above (tumour stage, grade and occurrence of BVI and/or LVI). The model of tumour aggressiveness also had a significant impact on survival rates. Multivariate analysis of these data revealed that the high aggressiveness profile remained as an independent prognostic factor of disease-free survival (HR 3.746; 95\% CI 1.244-11.285; $p=0.019$ ) and overall survival (HR 3.247; 95\% CI 1.015-10.388, $p=0.047$ ) (Table 3). 


\section{DISCUSSION}

In our study, we aimed to define urothelial bladder tumours with an aggressive phenotype by the combined analysis of clinicopathological and biological parameters. There were some limitations in the study. First, it included a population of bladder cancer patients that did not receive neoadjuvant or adjuvant treatments, and only some of the patients were treated with chemotherapy, in palliative setting, after progression (this may not be representative of all patients). Second, the study had a small sample size. However, despite these limitations, the classical prognostic factors, as stage pT3/pT4, grade III, infiltrating type of lesion, loco-regional dissemination and lymphovascular invasion were related to a worse outcome, as previously reported [21]. Heparanase immunorreactivity did not reveal any relevant prognostic information in our series. In pT3/pT4 tumours, the median overall survival time was 14.7 months, which was reduced to 9.2 months if the tumours were CD147 positive. In accordance with our results, several authors have found that CD147 overexpression seems to be correlated with a worse outcome and a cisplatin-resistant profile [12-14].

Using stage, grade and lymphovascular invasion as informative variables related to prognosis, and CD147 immunoexpression as an informative variable related to prognosis of patients with pT3/pT4 tumours, we attempted to organize a phenotype of UBC aggressiveness. Therefore, we developed a scoring system that classified patients with high grade superficial and invasive tumours in two aggressiveness profiles with different outcomes (low and high aggressiveness). This score proved to be an independent prognostic factor for 5-year disease-free survival and overall survival (95\% CI 1.244-11.285, $p=0.019$ for 5-year DFS; 95\% CI 1.015-10.388, $p=0.047$ for 5year OS). In the group of highly aggressive tumours, the rate of CD147 immunopositive cases was $87.2 \%$. However, one of the limitations of our study is the low number of cases involved, which is reflected in the wide confidence intervals. This score needs to be validated with a larger sample, preferentially in a multicentre study.

Nevertheless, our results suggest that CD147 overexpression may be a biological parameter related with worse prognosis. Xue et al have recently reported that CD147 immunoexpression is as an independent prognostic factor for bladder cancer patients, playing an important role in tumour progression [14]. Takata et al identified, in non-responder patients with invasive bladder cancer treated by M-VAC regimen, a gene (SLC16A3) that is closely associated with CD147 [9]. Als et al identified CD147 as a strong independent prognostic factor for response and survival 
after cisplatin-containing chemotherapy in patients with advanced bladder cancer [12].Yang et al found that CD147 is overexpressed in multidrug resistant (MDR) cancer cell lines, suggesting that during the development of a multidrug resistance phenotype, the expression of CD147 stimulates matrix metalloproteinases activity in MDR cells [25]. MDR1/P-glycoprotein or ABCB1 is one of the well characterized members of the energy-dependent drug efflux pumps that reduce intracellular accumulation of anticancer drugs, leading to the MDR phenotype [26]. Recent studies have demonstrated the co-localization of CD147 with MDR1, highlighting the possible cooperative roles of these molecules in cancer drug resistance and progression [27, 28]. In fact, increased expression of CD147 stimulates hyaluronan production, with MDR being induced in a hyaluronan-dependent manner $[29,30]$. The relationship between CD147 and MDR1 needs to be clearly elucidated. In our laboratory, studies are being conducted with bladder cancer cell lines that express CD147, in order to assess cisplatin resistance.

In conclusion, CD147 overexpression seems to be an important biomarker of prognosis that, when included in a scoring system of UBC aggressiveness, may help surgeons to identify patients who could benefit from a personalized therapeutic regimen. The definitive validation of this scoring system should be performed in a larger sample, in order to evaluate its internal consistency and its content, convergentdiscriminant and construct validity.

\section{Conflict of Interest Statement}

There is no conflict of interest in this manuscript. 


\section{REFERENCES}

1. Droller MJ. Bladder cancer: state-of-the-art care. CA Cancer J Clin 1998; 48: 269-84.

2. Kaufman DS, Shipley WU, Feldman AS. Bladder Cancer. Lancet 2009; 374: 23949.

3. Wiesner C, Pfitzenmaier J, Faldum A, Gillitzer R, Melchior SW, Thüroff JW. Lymph node metastases in non-muscle invasive bladder cancer are correlated with the number of transurethral ressections and tumour upstaging at radical cystectomy. BJU International 2005; 95: 301-5.

4. Sternberg CN, Donat SM, Bellmunt J et al. Chemotherapy for bladder cancer: treatment guidelines for neoadjuvant chemotherapy, bladder preservation, adjuvant chemotherapy, and metastatic cancer. Urology 2007; 69(1): 62-79.

5. von der Maase H, Hansen SW, Roberts JT et al. Gemcitabine and cisplatin versus methotrexate, vinblastine, doxorubicin and cisplatin in advanced or metastatic bladder cancer: results of a large, randomized, multinational, multicenter, phase III study. J Clin Oncol 2000; 1817: 3068-77.

6. Walz J, Shariat SF, Suardi $\mathrm{N}$ et al. Adjuvant chemotherapy for bladder cancer does not alter cancer-specific survival after cystectomy in a matched case control study. BJU Int 2008; 101(11): 1356-61.

7. Clark PE. Neoadjuvant versus adjuvant chemotherapy for muscle-invasive bladder cancer. Expert Rev Anticancer Ther 2009; 9(6): 821-30.

8. Grossman HB, Natale RB, Tangen $\mathrm{CM}$ et al. Neoadjuvant chemotherapy plus cystectomy compared with cystectomy alone for locally advanced bladder cancer. N Engl J Med 2003; 34: 859-66.

9. Takata R, Katagiri $T$, Kanehira $M$ et al. Predicting response to methotrexate, vinblastine, doxorubicin, and cisplatin neoadjuvant chemotherapy for bladder cancers through genome-wide gene expression profiling. Clin Cancer Res 2005; 11(7): 2625-36.

10. Kirk P, Wilson WC, Heddle C, Brown MH, Barclay AN, Halestrap AP. CD147 is tightly associated with lactate transporters MCT1 and MCT4 and facilitated their cell surface expression. EMBO 2000; 19: 3896-904.

11. Gabison EE, Hoang-Xuan T, Mauviel A, Menashi S. EMMPRIN/CD147, an MMP modulator in cancer, development and tissue repair. Biochimie 2005; 87: 361-8.

12. Als $A B$, Dyrskjøt $L$, von derMaase $H$ et al. Emmprin and Survivin Predict Response 
and Survival following Cisplatin-Containing Chemotherapy in Patients with Advanced Bladder Cancer. Clin Cancer Res 2007; 13(15): 4407-14.

13. Han $\mathrm{Z}, \mathrm{He} \mathrm{H}, \mathrm{Bi} \mathrm{X}$ et al. Expression and clinical significance of CD147 in genitourinary carcinomas. J Surg Res 2010; 160(2): 260-7.

14. Xue Y-J, Lu Q, Sun Z-X. CD147 overexpression is a prognostic factor and a potential therapeutic target in bladder cancer. Med Oncol 2010. Doi: 10.1007/s12032-010-9582-4.

15. Vlodavsky I, Friedmann Y. Molecular properties and involvement of heparanase in cancer metastasis and angiogenesis. J Clin Invest 2001; 108: 341-7.

16. Gohji $K$, Hirano $H$, Okamoto $M$ et al. Expression of three extracellular matriz degradative enzymes in bladder cancer. Int J Cancer 2001; 95: 295-301.

17. Cohen-Kaplan V, Naroditsky I, Zetser A, Ilan N, Vlodavsky I, Doweck I. Heparanase induces VEGF-C and facilitates tumour lymphangiogenesis. Int J Cancer 2008; 123: 2566-73.

18. Adams RH, Alitalo K. Molecular regulation of angiogenesis and lymphangiogenesis. Nature Rev 2007; 8: 464-78.

19. Harris EI, Lewin DN, Wang $\mathrm{HL}$ et al. Lymphovascular invasion in colorectal cancer: an interobserver variability study. Am J Surg Pathol 2008; 32(12): 181621.

20. Bolenz C, Herrmann E, Bastian PJ et al. Lymphovascular invasion is an independent predictor of oncological outcomes in patients with lymph nodenegative urothelial bladder cancer treated by radical cystectomy: a multicentre validation trial. BJU Int 2010. 106(4): 493-9.

21. Afonso J, Santos LL, Amaro T, Lobo F, Longatto-Filho A. The aggressiveness of urothelial carcinoma depends to a large extent on lymphovascular invasion - the prognostic contribution of related molecular markers. Histopathology 2009; 55: 514-24.

22. Amin MB, Srigley JR, Grignon DJ, Reuter VE, Humphrey PA, Cohen MB, Hammond AEH. Urinary bladder cancer protocols and checklists. Northfield, IL: College of American Pathologists; 2005.

23. Greene FL, Page DL, Fleming ID, Fritz A, Balch CM, Haller DG, Morrow M, eds. AJCC Cancer Staging Manual. 6th ed. New York: Springer Verlag; 2002.

24. Eble JN, Sauter G, Epstein JI, Sesterhenn IA, eds. World Health Organization Classification of Tumours. Pathology and Genetics of Tumours of the Urinary System and Male Genital Organ. Lyon: IARC Press; 2004. 
25. Yang JM, Xu Z, Wu H, Zhu H, Wu X, Hait WN. Overexpression of extracellular matrix metalloproteinase inducer in multidrug resistant cancer cells. Mol Cancer Res 2003; 1: 420-27.

26. German UA. P-glycoprotein - a mediator of multidrug resistance in tumour cells. Eur J Cancer 1996; 32A: 927-944.

27. Chen H, Wang L, Beretov J, Hao J, Xiao W, Li Y. Co-expression of CD147/EMMPRIN with monocarboxylate transporters and multidrug resistance proteins is associated with epithelial ovarian cancer progression. Clin Exp Metastasis 2010; 27(8):557-569.

28. Hao J, Chen H, Madigan MC et al. Co-expression of CD147 (EMMPRIN), CD44v310, MDR1 and monocarboxylate transporters is associated with prostate cancer drug resistance and progression. $\mathrm{Br}$ ] Cancer 2010; 103(7): 1008-1018.

29. Misra S, Ghatak S, Zoltan-Jones A, Toole BP. Regulation of multidrug resistance in cancer cells by hyaluronan. J Biol Chem 2003; 278: 25285-8.

30. Marieb EA, Zoltan-Jones A, Li R et al. Emmprin promotes anchorage-independent growth in human mammary carcinoma cells by stimulating hyaluronan production. Cancer Res 2004; 64: 1229-1232. 
Table 1. Clinicopathological parameters

\begin{tabular}{|c|c|c|}
\hline \multirow[t]{2}{*}{ Gender } & Male & 64 \\
\hline & Female & 13 \\
\hline Age & Median (range) & $71(41-83)$ \\
\hline \multirow{3}{*}{ Tumour stage } & Group 1 & 16 \\
\hline & Group 2 & 12 \\
\hline & Group 3 & 49 \\
\hline \multirow{2}{*}{ Grade } & II & 20 \\
\hline & III & 57 \\
\hline \multirow{3}{*}{$\begin{array}{l}\text { Morphological } \\
\text { type of lesion }\end{array}$} & Non-invasive papillary & 12 \\
\hline & In situ & 4 \\
\hline & Infiltrating & 61 \\
\hline \multirow{2}{*}{$\begin{array}{c}\text { Lymphovascular } \\
\text { invasion } \\
\text { (H\&E stain) }\end{array}$} & Yes & 37 \\
\hline & No & 40 \\
\hline \multirow{2}{*}{$\begin{array}{l}\text { Loco-regional } \\
\text { dissemination }\end{array}$} & Yes & 22 \\
\hline & No & 55 \\
\hline \multirow{2}{*}{ Recurrence } & Yes & 58 \\
\hline & No & 19 \\
\hline \multirow{2}{*}{$\begin{array}{l}\text { Clinical } \\
\text { Outcome }\end{array}$} & Dead, bladder cancer & 54 \\
\hline & $\begin{array}{l}\text { Alive, lost to follow-up, } \\
\text { or dead, other causes }\end{array}$ & 23 \\
\hline
\end{tabular}


Table 2. Correlation between 5-year disease-free survival and overall survival rates, and clinicopathological variables, biological parameters and tumour aggressiveness scoring system

\begin{tabular}{|c|c|c|c|c|c|c|}
\hline & & \\
\hline & & $\mathbf{n}$ & 5-year DFS rate & $p^{*}$ & 5-year OS rate & $p^{*}$ \\
\hline \multirow{2}{*}{ Gender } & Male & 64 & $21.5 \%$ & \multirow{2}{*}{ ns } & $30.7 \%$ & \multirow{2}{*}{ ns } \\
\hline & Female & 13 & $34.6 \%$ & & $34.2 \%$ & \\
\hline \multirow{2}{*}{ Age } & $\leq 71$ years & 41 & $27.0 \%$ & \multirow{2}{*}{ ns } & $35.5 \%$ & \multirow{2}{*}{ ns } \\
\hline & $>71$ years & 36 & $20.6 \%$ & & $30.3 \%$ & \\
\hline \multirow{3}{*}{ Stage } & Group 1 & 16 & $33.7 \%$ & \multirow{3}{*}{0.008} & $43.0 \%$ & \multirow{3}{*}{0.004} \\
\hline & Group 2 & 12 & $27.8 \%$ & & $45.8 \%$ & \\
\hline & Group 3 & 49 & $20.4 \%$ & & $23.7 \%$ & \\
\hline \multirow{2}{*}{ Grade } & II & 20 & $42.7 \%$ & \multirow{2}{*}{0.006} & $57.6 \%$ & \multirow{2}{*}{0.001} \\
\hline & III & 57 & $17.2 \%$ & & $22.3 \%$ & \\
\hline \multirow{3}{*}{$\begin{array}{l}\text { Morphological } \\
\text { type of lesion }\end{array}$} & Non-invasive papillary & 12 & $27.8 \%$ & \multirow{3}{*}{0.046} & $42.8 \%$ & \multirow{3}{*}{0.039} \\
\hline & In situ & 4 & $50.0 \%$ & & $50.0 \%$ & \\
\hline & Infiltrating & 61 & $21.5 \%$ & & $28.1 \%$ & \\
\hline \multirow{2}{*}{$\begin{array}{c}\text { Lymphovascular } \\
\text { invasion } \\
\text { (H\&E stain) }\end{array}$} & Negative & 40 & $29.4 \%$ & \multirow{2}{*}{0.031} & $41.5 \%$ & \multirow{2}{*}{0.003} \\
\hline & Positive & 37 & $18.9 \%$ & & $21.0 \%$ & \\
\hline \multirow{2}{*}{$\begin{array}{l}\text { Loco-regional } \\
\text { dissemination }\end{array}$} & Negative & 55 & $28.1 \%$ & \multirow{2}{*}{0.042} & $40.1 \%$ & \multirow{2}{*}{0.001} \\
\hline & Positive & 22 & $13.6 \%$ & & $10.0 \%$ & \\
\hline \multirow{2}{*}{ CD147 expression } & Negative & 18 & $22.2 \%$ & \multirow{2}{*}{ ns } & $23.9 \%$ & \multirow{2}{*}{ ns } \\
\hline & Positive & 59 & $24.3 \%$ & & $34.2 \%$ & \\
\hline \multirow{2}{*}{$\begin{array}{l}\text { Heparanase } \\
\text { expression }\end{array}$} & Negative & 42 & $20.0 \%$ & \multirow{2}{*}{ ns } & $34.4 \%$ & \multirow{2}{*}{ ns } \\
\hline & Positive & 35 & $28.6 \%$ & & $28.6 \%$ & \\
\hline \multirow{2}{*}{$\begin{array}{l}\text { Blood vessel } \\
\text { invasion } \\
\text { (CD31 stain) }\end{array}$} & Negative & 66 & $26.5 \%$ & \multirow{2}{*}{0.004} & $35.2 \%$ & ? \\
\hline & Positive & 11 & $9.1 \%$ & & $9.1 \%$ & \\
\hline Lymphatic vessel & Negative & 46 & $30.3 \%$ & & $36.2 \%$ & \\
\hline (D2-40 stain) & Positive & 31 & $14.0 \%$ & & $24.3 \%$ & \\
\hline Tumour & $0-2$ positive parameters & 30 & $43.3 \%$ & & $54.8 \%$ & \\
\hline Scoring System** & 3-5 positive parameters & 47 & $11.9 \%$ & & $17.0 \%$ & \\
\hline
\end{tabular}

* Log-Rank or Breslow tests

** Includes T3/T4 pathologic stage, grade III, occurrence of blood vessel invasion by malignant emboli, occurrence of lymphatic vessel invasion by isolated malignant cells and CD147 immunoexpression

DFS- disease-free survival, OS- overall survival, ns- not significant 
Table 3. Multivariate survival-time regression for predictors of 5-year disease-free survival and overall survival after radical cystectomy for urothelial bladder cancer

\begin{tabular}{|c|c|c|c|c|c|c|c|}
\hline & \multicolumn{3}{|c|}{ 5-year DFS rate } & \multicolumn{3}{|c|}{ 5-year OS rate } \\
\hline & & HR & 95\% CI & $\boldsymbol{p}$ & HR & 95\% CI & $p$ \\
\hline \multirow{3}{*}{ Stage } & Group 1 & 1.000 & - & - & 1.000 & - & - \\
\hline & Group 2 & 0.741 & $0.251-2.186$ & 0.587 & 0.694 & $0.211-2.288$ & 0.549 \\
\hline & Group 3 & 0.672 & $0.230-1.961$ & 0.467 & 0.783 & $0.243-2.524$ & 0.682 \\
\hline \multirow{2}{*}{ Grade } & II & 1.000 & - & - & 1.000 & - & - \\
\hline & III & 1.183 & $0.462-3.030$ & 0.725 & 1.598 & $0.557-4.585$ & 0.383 \\
\hline \multirow{2}{*}{$\begin{array}{l}\text { Blood vessel } \\
\text { invasion } \\
\text { (CD31 stain) }\end{array}$} & Non-occurrence & 1.000 & - & - & 1.000 & - & - \\
\hline & Occurrence & 1.653 & $0.801-3.413$ & 0.174 & 1.728 & $0.835-3.578$ & 0.141 \\
\hline \multirow{2}{*}{$\begin{array}{l}\text { Lymphatic } \\
\text { vessel invasion } \\
\text { (D2-40 stain) }\end{array}$} & Non-occurrence & 1.000 & - & & 1.000 & - & - \\
\hline & Occurrence & 0.864 & $0.463-1.613$ & 0.647 & 0.798 & $0.416-1.534$ & 0.499 \\
\hline \multirow{2}{*}{$\begin{array}{c}\text { Tumour } \\
\text { Aggressiveness } \\
\text { Scoring } \\
\text { System* }\end{array}$} & $\begin{array}{l}0-2 \text { positive } \\
\text { parameters }\end{array}$ & 1.000 & & & 1.000 & - & - \\
\hline & $\begin{array}{l}\text { 3-5 positive } \\
\text { parameters }\end{array}$ & 3.746 & $1.244-11.285$ & 0.019 & 3.247 & $1.015-10.388$ & 0.047 \\
\hline
\end{tabular}

* Includes T3/T4 pathologic stage, grade III, occurrence of blood vessel invasion by malignant emboli, occurrence of lymphatic vessel invasion by isolated malignant cells and CD147 immunoexpression

DFS- disease-free survival, OS- overall survival, HR- hazard ratios, CI- confidence interval 


\section{FIGURE LEGENDS}

Figure 1: Immunohistochemical positive reactions for CD147 [(a), x200 amplification; (b), x100 amplification] and heparanase [(c), x100 amplification] in urothelial bladder carcinoma cells. (a) A non-invasive case showing superficial malignant cells positive for CD147; (b) an invasive case showing the cytoplasmic membranes of the inner layers of malignant cells stained for CD147; (c) an invasive case showing the strong immunoreaction for heparanase in the invasive front of the tumour.

Figure 2: Kaplan-Meier curves demonstrating 5-year disease-free survival (a) and 5year overall survival (b) based on the tumour aggressiveness scoring system (includes T3/T4 pathologic stage, grade III, occurrence of blood vessel invasion by malignant emboli, occurrence of lymphatic vessel invasion by isolated malignant cells and CD147 overexpression) $(n=77)$. 

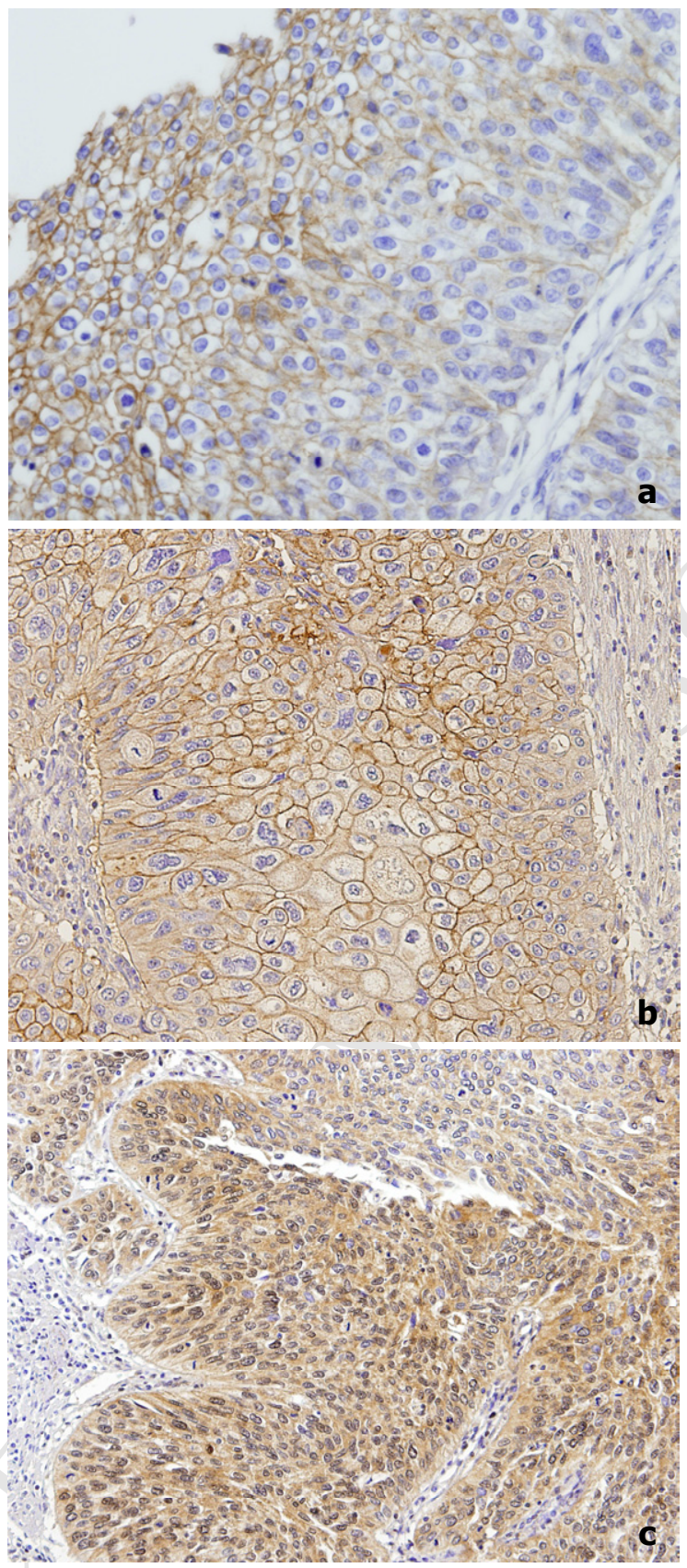

Figure 1 

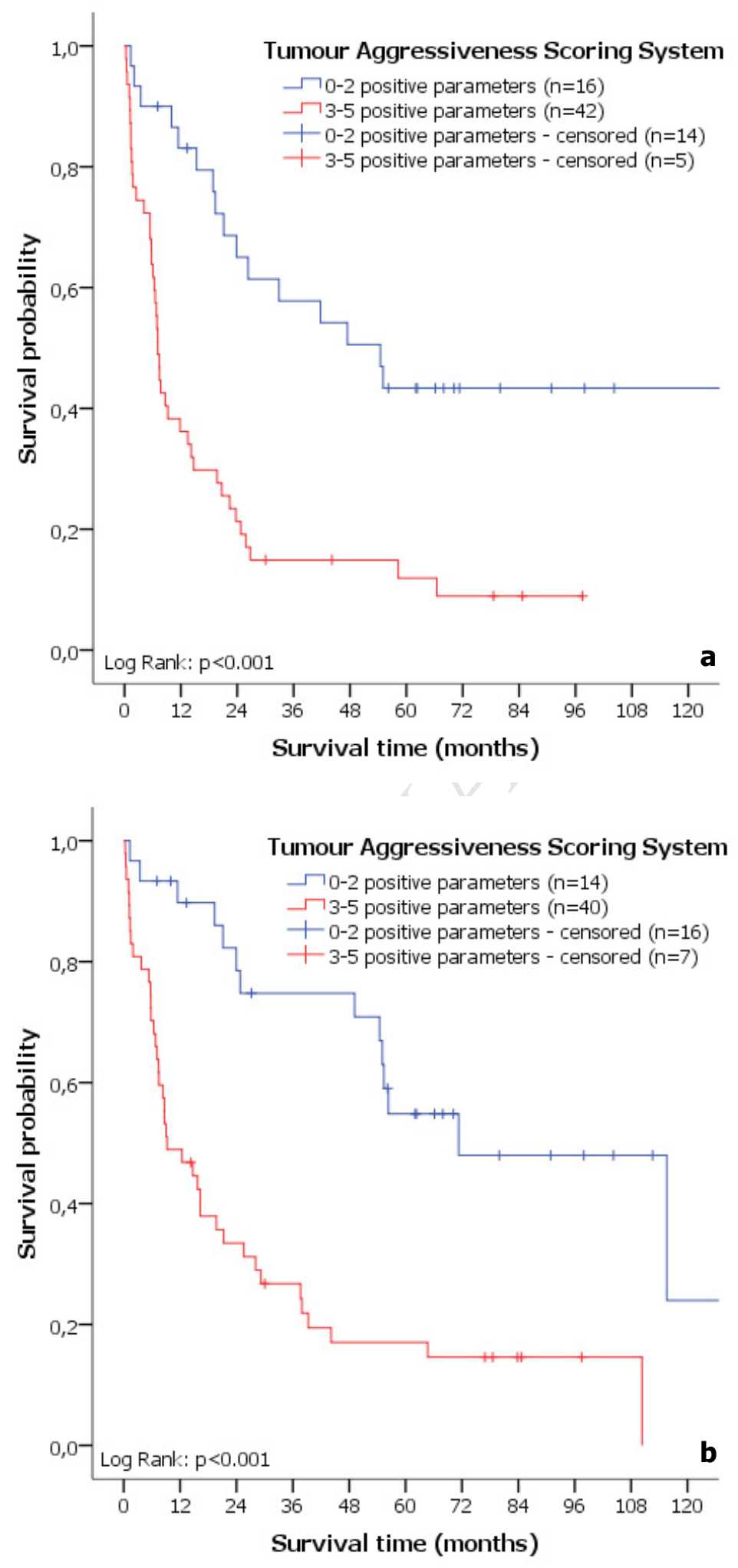

Figure 2 